\begin{tabular}{|l|l|l||}
\hline \multicolumn{2}{|c|}{ PublisherInfo } \\
\hline \hline PublisherName & $:$ & BioMed Central \\
\hline \hline PublisherLocation & $:$ & London \\
\hline \hline PublisherImprintName & $:$ & BioMed Central \\
\hline \hline
\end{tabular}

\title{
Radiological review of interval cancers in Stockholm
}

\begin{tabular}{|l|l|l||}
\hline \multicolumn{2}{|c||}{ ArticleInfo } \\
\hline \hline ArticleID & $:$ & 3652 \\
\hline \hline ArticleDOI & $:$ & $10.1186 /$ bcr-1999-66630 \\
\hline \hline ArticleCitationID & $:$ & 66630 \\
\hline \hline ArticleSequenceNumber & $:$ & 18 \\
\hline \hline ArticleCategory & $:$ & Paper Report \\
\hline \hline ArticleFirstPage & $:$ & 1 \\
\hline \hline ArticleLastPage & $:$ & 4 \\
\hline \hline & & RegistrationDate : 1999-7-12 \\
\hline ArticleHistory & $:$ & OnlineDate \\
\hline ArticleCopyright & $:$ & Current Science Ltd1999-7-12 \\
\hline \hline ArticleGrants & $:$ & \\
\hline \hline ArticleContext & $:$ & 1305822 \\
\hline \hline
\end{tabular}




\section{Keywords}

breast neoplasm, interval cancers, mammography, mass screening

\section{Introduction}

Interval cancers are those cancers which present between screening examinations in women who previously screened negative. They can be classified in a review process comparing diagnostic mammograms with those from the preceding screen. Of all intervals, some were not present at the time of screening but developed fast enough to present symptomatically (true intervals); some were not evident mammographically even at diagnosis (occult); some showed non-specific signs at screening but were not sufficiently suspicious to warrant further investigations (minimal sign) and some were evident at screening but were missed or incorrectly interpreted (false negative). The rate of false negatives in a screening programme is a measure of radiologists' performance. However, the method of review and classification will determine the proportion of cases classified as false negative.

\section{Aims}

To determine the effect on interval cancer classification of mixing interval cancer screening films with other films to approximate the normal screening situation, and of including external (from other screening units) as well as internal (from the original screening unit) reviewers in the review process.

\section{Comments}

Interval cancers are an expected but unpleasant aspect of screening programmes. Their numbers and prognosis have an important influence on programme performance. Investigating reasons for their occurrence is therefore an essential activity. This paper illustrates that the review method used can influence the apparent result and highlights the need for consistency in methodology when comparing different programmes. In this study readers were no less likely to classify a cancer as false negative if it originated from their own unit. However, it should not be assumed that this would be the case everywhere. 


\section{Methods}

Interval cancer cases in women screened by two of the five screening units in Stockholm in the period 1989-1991 were reviewed. For mixed reviewing, 59 cases from one unit were randomly mixed in a ratio 1:8 (59:416) with other screening films which showed mainly no malignancy (390) plus a few screen detected malignancies (15) or benign breast disease (11). Two readers from each of four of the screening units reviewed the original films to try to identify correctly the site of the subsequent cancer. The readers were not given access to the symptomatic films. For investigation of difference between external and internal reviewers, 103 cases were reviewed. External reviewers comprised one reader from each of the three units not providing cases; internal reviewers comprised two readers from each of the two units providing cases.

\section{Results}

In mixed reviewing the three reviewers showed similar false negative rates for 59 cases $(15 \%, 15 \%$, $12 \%)$. However, two of the three reviewers selected almost as many cases incorrectly as correctly. Rates for incorrectly recalling normal cases varied $(3 \%, 8 \%, 11 \%)$. In non-mixed reviewing (when only interval cases were classified) false negative rates were almost doubled (27\%, 27\%, 25\%). One unit recalled almost as many interval cases for the wrong area/wrong breast as correct cases. There was no evidence that external reviewers classified films differently from internal reviewers. The minimum number of cases which could be considered as missed was 7\% (4 of 59 cases selected by all units using both review methods). The maximum number of cases which could be considered to be missed in nonmixed review was $34 \%$ (20 of 59 cases correctly selected by one of the reviewers); in mixed review it was $22 \%$ (13 of 59 cases).

\section{Discussion}

Mixing interval cases with normal mammograms more closely reflects the screening situation but identifies considerably fewer missed cases than in non-mixed review. These results $(7 \%$ to $34 \%$ missed cases depending on review method used) are in approximate agreement with results elsewhere where rates varied between $4 \%$ and 56\% with mixing of cases:non-cases in the ratio 1:3. Lack of influence of internal/external status of reviewer on results may be influenced by the length of time since case occurred or by internal reviewers? knowledge that external reviewers were also involved. Most interval cancers (66\%-78\%) were not regarded as missed cases whichever review procedure was used. The procedure provides a useful teaching and quality control exercise. 


\section{References}

1. Moberg K, Grundstrom H, Tornberg S, Lundquist H, Svane G, Havervall L, Muren C: Two models for radiological reviewing of interval cancers. J Med Screen. 1999, 6: 35-39.

This PDF file was created after publication. 